\title{
Fast Modulation of Executive Function by Language Context in Bilinguals
}

\author{
Yan Jing $\mathrm{Wu}^{1}$ and Guillaume Thierry ${ }^{1,2}$ \\ ${ }^{1}$ School of Psychology and ${ }^{2}$ Economic and Social Research Council Centre for Research on Bilingualism in Theory and Practice, Bangor University, Bangor \\ LL57 2AS, United Kingdom
}

\begin{abstract}
Mastering two languages has been associated with enhancement in human executive control, but previous studies of this phenomenon have exclusively relied on comparisons between bilingual and monolingual individuals. In the present study, we tested a single group of WelshEnglish bilinguals engaged in a nonverbal conflict resolution task and manipulated language context by intermittently presenting words in Welsh, English, or both languages. Surprisingly, participants showed enhanced executive capacity to resolve interference when exposed to a mixed compared with a single language context, even though they ignored the irrelevant contextual words. This result was supported by greater response accuracy and reduced amplitude of the P300, an electrophysiological correlate of cognitive interference. Our findings introduce a new level of plasticity in bilingual executive control dependent on fast changing language context rather than long-term language experience.
\end{abstract}

\section{Introduction}

Bilinguals outperform monolinguals in a number of nonlinguistic tests of executive function (Bialystok et al., 2004; Costa et al., 2008). One explanation for this bilingual advantage is that managing two languages requires constantly selecting words in the intended language and inhibiting words from the unintended language, processes that are thought to engender a highly efficient control mechanism (Green, 1998; Bialystok, 2001, 2007). Furthermore, the experience of multiple languages has been shown to facilitate the development of executive function in children and protect elderly people against executive control decline (Bialystok et al., 2006; Kovács and Mehler, 2009; Gold at al., 2013).

However, bilinguals and monolinguals differ not only based on language ability but also other variables, such as socioeconomic status and ethnic origin. Indeed, the latter two factors have been hypothesized to account for the bilingual advantage (Sabbagh et al., 2006; Morton and Harper, 2007). The methodological dilemma is that preexisting differences between bilingual and monolingual individuals make it difficult, if not impossible, to match participants across groups on language-dependent variables, because language plays an important role in almost every aspect of life. Therefore, it remains to be established whether bilingualism directly enhances cognitive abilities or whether the

Received Oct. 8, 2012; revised June 10, 2013; accepted July 10, 2013.

Author contributions:Y.J.W. designed research;Y.J.W. performed research;Y.J.W. and G.T. analyzed data; Y.J.W. and G.T. wrote the paper.

G.T. was supported by the Economic and Social Research Council (Grant RES-000-23-0095), and Y.J.W. and G.T. were supported by the European Research Council (Grant ERC-StG-209704). We thank Ellen Bialystok, Angela Friederici, Judy Kroll, Marilyn Vihman, Janet Van Hell, and four anonymous reviewers for advice and comments on this manuscript.

The authors declare no competing financial interests.

This article is freely available online through the J Neurosci Author Open Choice option.

Correspondence should be addressed to Prof. Guillaume Thierry, School of Psychology, Bangor University, Bangor LL57 2AS, UK. E-mail: g.thierry@bangor.ac.uk.

DOI:10.1523/JNEUROSCI.4760-12.2013

Copyright $\odot 2013$ the authors $\quad 0270-6474 / 13 / 3313533-05 \$ 15.00 / 0$ bilingual advantage is an artifact prompted by languageassociated confounding variables.

Even if we consider the existence of the bilingual advantage well established, it is unknown whether such advantage is permanent or modulated by the immediate cognitive context. Unlike monolinguals, bilinguals can either use one language (monolingual context) or both their languages (bilingual context) in a given interaction. If bilingualism bestows a generic and permanent executive control advantage to bilinguals, enhanced cognitive control should be independent of language context. If, on the contrary, the bilingual advantage is context dependent, enhancement should be most salient when bilinguals are exposed to their two languages.

The present study examined this hypothesis by testing effects of the immediate language context within a group of early Welsh-English bilinguals. Executive functioning was tested in a simplified version of the flanker task (Fan et al., 2002). Participants were instructed to press a button to indicate the direction of a central arrow (i.e., the target) surrounded by congruent or incongruent flanker arrows. Occasionally, a word was presented instead of arrows, which participants were instructed to ignore. This paradigm, therefore, differs radically from that used in previous studies of cognitive control looking into sequential effects of congruent and incongruent trials on performance (Botvinick et al., 1999; Kerns et al., 2004). The experiment contained three blocks in which the contextual words to be ignored were in Welsh, in English, or in either of the two languages (Fig. 1). We expected trials in which the direction of flanker arrows was incongruent with that of the central arrow to require more inhibitory control than congruent trials, thereby increasing the amplitude of the P300 wave of ERPs. A modulation of the P300 congruency effect by the type of words presented incidentally would indicate that bilinguals experience fast modulation of their executive system by language context.

\section{Materials and Methods}

Participants. Eighteen right-handed (Oldfield, 1971) Welsh-English bilinguals (nine females and nine males; $20.4 \pm 2.1$ years) with normal or 


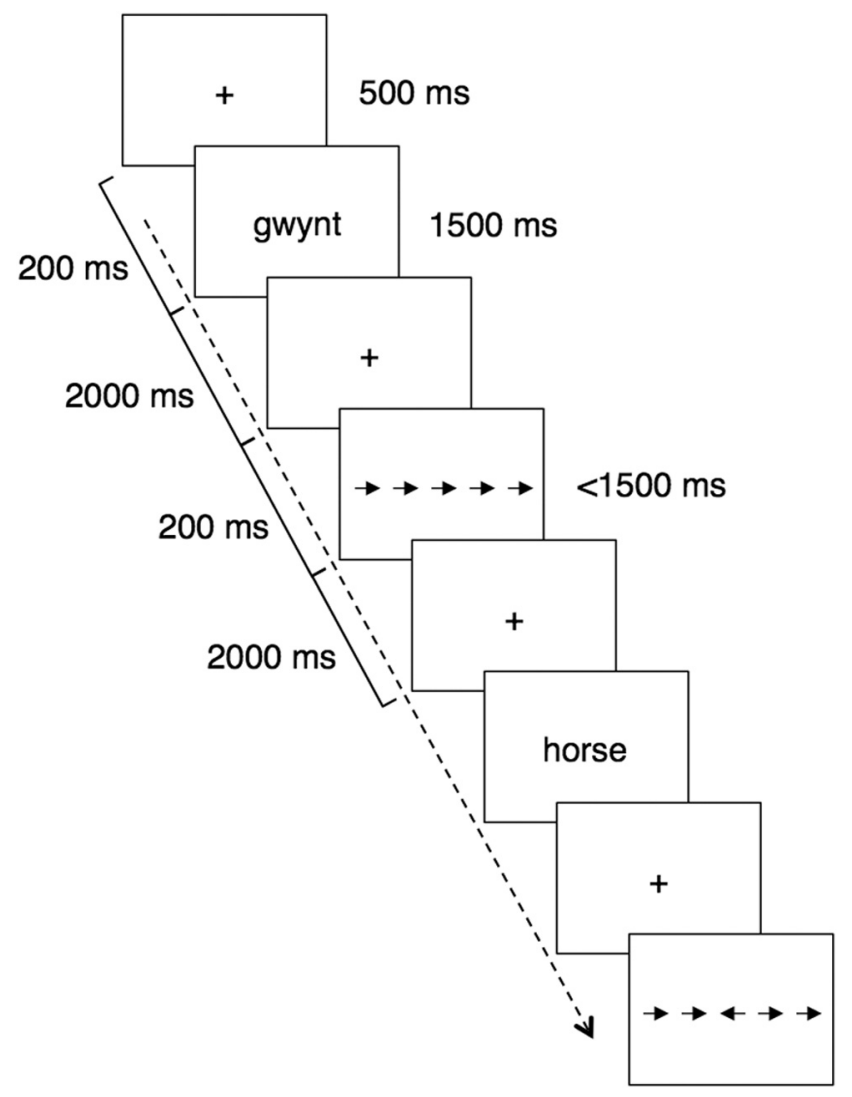

Figure 1. Experimental design and stimulus examples. Each trial began with a fixation cross that lasted for $500 \mathrm{~ms}$ and was followed by a blank screen of $200 \mathrm{~ms}$. The stimulus was then presented at the same location as the fixation cross for $1500 \mathrm{~ms}$ or as soon as the participant responded to it. The intertrial interval was $2000 \mathrm{~ms}$.

corrected-to-normal vision took part in the experiment. No participants reported neurological or other mental issues. Bilingual participants learned both languages at an early age (mean age of acquisition of Welsh, $2.1 \pm 0.7$ years; mean age of acquisition of English, $2.8 \pm 0.9$ years) and did not speak any other language. They used both languages on a daily basis, at home and at university. Bilingual participants rated their global proficiency in Welsh at $9.8 \pm 0.5$ and their proficiency in English at $8.9 \pm$ 1.1 on a scale from 1 (very poor) to 10 (perfectly fluent). The rating was based on reading, writing, listening, and speaking skills.

Stimuli. Stimuli were arrow displays featuring five horizontal arrows with the arrow in the center either matching the direction of the flanking arrows or not, thus making up four stimulus types: (1) all arrows directed to the left, (2) all arrows directed to the right, (3) all arrows but the center one directed to the left, and (4) all arrows but the center one directed to the right. Word stimuli were 270 high-frequency nouns in English and Welsh, with neutral affective valence (Bradley and Lang, 1999), distributed across three blocks of 90 flanker trials (arrow displays). The blocks differed in terms of the language(s) of the intervening words (i.e., English, Welsh, or mixed). In the monolingual blocks, all words were in English or Welsh. In the mixedlanguage block, half of the words were in English and the other half were in Welsh. Repeated-measures ANOVAs conducted on lexical frequency, word concreteness, and number of letters (Coltheart, 1981) revealed no significant differences between the three experimental blocks (all $p s>0.1$ ). Word order was randomized within each block. We prepared 18 experimental stimulus sequences to randomize presentation between participants. Words susceptible of causing semantic interference with the flanker task (e.g., left, right, middle) were avoided.

Procedure. Participants sat on a chair $1 \mathrm{~m}$ away from the screen in a quiet room. They signed a written consent form before taking part in the study that was approved by the ethics committee of Bangor University (Wales, UK). The flanker task was a simplified version of the test originally described by
Fan et al. (2002): (1) flanker trials were intermixed with pseudorandom presentations of single words; and (2) all stimuli were presented at the center of the screen to avoid vertical eye movements. Each trial had the following sequence: (1) a fixation cross (+) appeared at the center of the screen for 500 ms; (2) a blank screen appeared for $200 \mathrm{~ms}$; (3) the stimulus was presented until the participants responded or for a maximum duration of $1500 \mathrm{~ms}$; and (4) a $2000 \mathrm{~ms}$ intertrial interval occurred. The relatively long intertrial interval reduced the eventuality of carryover effects. Participants were instructed to indicate whether the central arrow in flanker stimuli pointed to the left (left button press) or the right (right button press) with the corresponding index finger and to ignore intervening word presentations (i.e., not to make any response to them). Block order was fully counterbalanced between participants. Participants took a short break between experimental blocks. The language in which the filler words were presented was mentioned to the participants, who were also reminded that these words were irrelevant and should be ignored. After the experiment, participants were given a surprise questionnaire in which they had to identify words previously presented in the experiment intermixed with 270 new words matched in terms of lexical frequency (Coltheart, 1981). Participants were able to recognize $>70 \%$ of the words (false alarms were marked negatively), and the error rate did not differ significantly between experimental blocks ( $p$ s $>0.1$ in all pairwise comparisons).

$E R P$ recording. Electrophysiological data were recorded in reference to $\mathrm{Cz}$ at a rate of $1 \mathrm{kHz}$ from $64 \mathrm{Ag} / \mathrm{AgCl}$ electrodes placed according to the extended 10-20 convention. Impedances were kept $<5 \mathrm{k} \Omega$. Electroencephalogram activity was filtered on-line bandpass between 0.1 and 200 $\mathrm{Hz}$ and refiltered off-line with a $25 \mathrm{~Hz}$, low-pass, zero-phase shift digital filter. Eye blinks were mathematically corrected, and remaining artifacts were manually dismissed (Gratton et al., 1983). Continuous recordings were cut into epochs ranging from -100 to $1000 \mathrm{~ms}$ after the onset of each flanker trial. Signals exceeding $\pm 75 \mu \mathrm{V}$ in any given epoch were automatically discarded. There was a minimum of 60 valid epochs per condition in every subject. Baseline correction was performed in reference to prestimulus activity, and individual averages were digitally rereferenced to the global average reference. ERP data were collected simultaneously to behavioral data.

ERP data analysis. The temporal window of the P300 effect was determined by means of pairwise millisecond-by-millisecond comparisons between the congruent and incongruent conditions considered significant when differences were above threshold $(p<0.05)$ for $>30$ ms over a minimum of nine clustered electrodes (Rugg et al., 1993; Thierry et al., 2003). As a result, the mean ERP amplitudes between 500 and $750 \mathrm{~ms}$, in which the two conditions were significantly different in all three blocks, were subjected to a repeated-measures ANOVA with congruency (congruent/incongruent) and language context (English, Welsh, and mixed) as within-subject factors. Topographical analyses were based on mean amplitudes measured over 63 electrodes distributed over the entire scalp. Interactions involving the electrode factor were controlled using within-condition vector normalization (McCarthy and Wood, 1985). A Greenhouse-Geisser correction was performed where applicable. The P300 effect was maximal over the central parietal scalp (i.e.,C1, Cz, C2, P1, Pz, P2, CP1, CPz, and CP2).

\section{Results}

As expected, reaction times $\left(F_{(1,17)}=23.22 ; p<0.001\right)$ and error rates $\left(F_{(1,17)}=32.46 ; p<0.001\right)$ were reduced in congruent compared with incongruent trials (Fig. 2), showing a classic flanker interference effect (Eriksen and Eriksen, 1974). However, whereas language processing context did not significantly affect reaction times $\left(F_{(2,34)}=0.34 ; p>0.1\right)$ or error rates $\left(F_{(2,34)}=\right.$ 2.47; $p>0.1)$, a significant interaction between experimental block (i.e., English, Welsh, and mixed) and congruency (i.e., congruent and incongruent) was found on error rates $\left(F_{(2,34)}=5.20\right.$; $p<0.01)$. Post hoc analysis showed that error rates for incongruent trials were reduced in the mixed block compared with each of the two monolingual blocks ( $p s<0.05$ ), suggesting that conflict resolution was easier in the mixed-language context. 


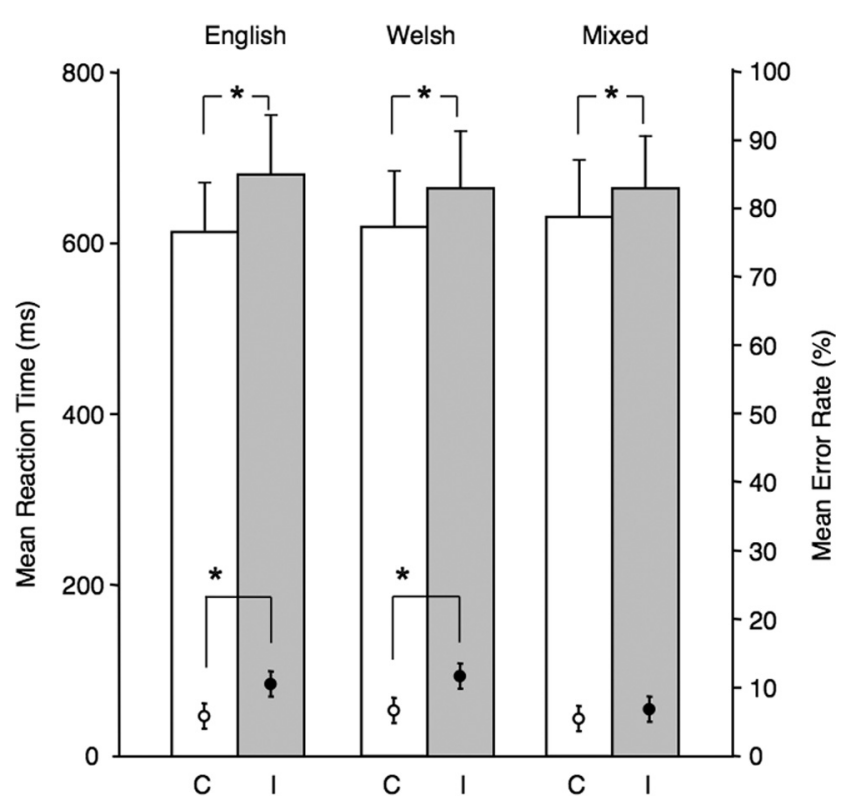

Figure 2. Reaction times (bars; left axis) and error rates (bullets; right axis) in the flanker task for the English, Welsh, and mixed contexts. For reaction time data, the congruent condition (C) is presented in white and the incongruent condition (I) in gray. For error data, the congruent condition is presented in white and the incongruent condition is in black. The asterisks indicate significant differences $(p<0.05)$. Error bars depict SEM in all cases.

Consistent with the behavioral results, a main effect of congruency was found on ERP mean amplitude measured between 500 and $750 \mathrm{~ms}$ after stimulus onset $\left(F_{(1,17)}=18.73 ; p<0.001\right)$. Compared with congruent trials, incongruent trials elicited a greater positivegoing waveform maximal over centroparietal regions, consistent with a P300 effect (Fig. 3), which previous studies have established as an index of inhibition control in the flanker paradigm (Polich, 2007; Neuhaus et al., 2010). Note that the $\mathrm{P} 300$ was expected in a relatively late time window since it was elicited by low probability events requiring explicit responses. Such a paradigm typically elicits a P3b with a distribution slightly more posterior and a latency slightly greater than that observed for the P3a.

Critically, a significant interaction between congruency and experimental block was found in this time window $\left(F_{(2,34)}=\right.$ $3.71 ; p<0.05$; Fig. 4$)$ : ERP mean amplitude for incongruent trials was reduced in the mixed compared with the monolingual blocks ( $p$ s $<0.05$ ), showing that participants suffered less interference from incongruent flankers in a mixed-language context. Moreover, millisecond-by-millisecond analyses of averaged ERP differences performed independently across groups showed that the congruency effect was of shorter duration in the mixed (500-757 $\mathrm{ms})$ than in the monolingual $(500-800+\mathrm{ms})$ blocks.

\section{Discussion}

The behavioral and electrophysiological findings converge in showing that the mixed-language context, compared with the monolingual context, facilitates nonlinguistic conflict resolution. Since the same participants were tested in all conditions, the present findings cannot be accounted for by spurious differences between groups. To our knowledge, this is the first evidence of on-line interaction between two cognitive factors generally considered independent (i.e., language processing context and nonlinguistic executive interference), lending strong support to theories that relate enhancement in executive control to language abilities. However, the direction of this cross-domain interaction remains counterintuitive since the traditional bilingual advan-
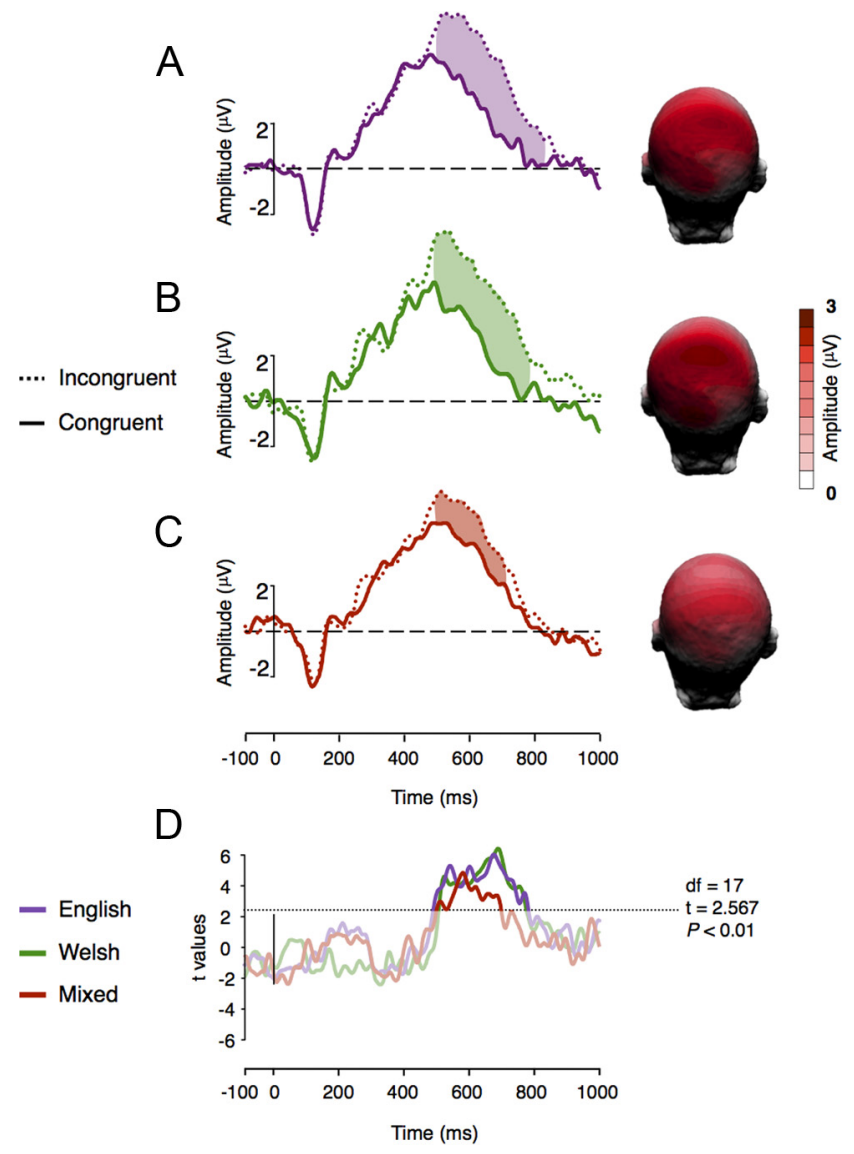

Figure 3. $\quad A-C$, Event-related brain potentials and topographies elicited in the flanker task in the English $(\boldsymbol{A})$, Welsh $(\boldsymbol{B})$, and mixed $(\boldsymbol{C})$ contexts. The waveforms depict linear derivations of brain potentials from nine electrodes $(\mathrm{C1}, \mathrm{C2}, \mathrm{CZ}, \mathrm{P1}, \mathrm{P2}, \mathrm{Pz}, \mathrm{CP} 1, \mathrm{CP} 2$, and $\mathrm{CPz})$. The shaded areas represent significant differences between conditions (e.g., $p<0.05$ ) over a minimal period of $30 \mathrm{~ms}$. The scaled topographies show the ERP differences elicited by the flanker effect. $\boldsymbol{D}$, Millisecond-by-millisecond $t$ test comparisons between congruent and incongruent conditions (purple, English; green, Welsh; red, Mixed). The dotted line represents the threshold of significant differences.

tage hypothesis assumes that controlling two languages in parallel is a mental burden, thus requiring more, not less, cognitive resources. The most parsimonious explanation for the present findings is that, since it is task irrelevant, the incidental processing of words from two languages did not directly compete for cognitive resources with nonverbal conflict resolution. Instead, the mixed-language context shifted the executive system to an enhanced functional level, thus improving the effectiveness of nonverbal conflict resolution. This explanation is in line with theories of reactive adjustment in human cognitive control. For example, studies have shown that the processing of conflict is enhanced when the brain is primed to a state of higher cognitive control by previous tasks engaging the same cognitive operations (Gratton et al., 1992; Botvinick et al., 1999; Kerns et al., 2004; Kerns, 2006). The present findings shed new light in this domain by demonstrating that executive function is modulated not only by explicit nonverbal conflict operations but also by implicit and irrelevant contextual language cues (i.e., a cross-domain interaction).

This account is also fully consistent with recent neuroimaging studies revealing patterns of brain activations that are considered specific to bilingual participants performing nonlinguistic conflict tasks (Bialystok et al., 2005; Garbin et al., 2010). Some of the between-group contrasts were found in brain regions such as the left caudate and dorsal anterior cingulate cortex, which have also 
been shown to be involved in bilingual language control (Crinion et al., 2006; Abutalebi et al., 2008, 2012). However, despite evidence of convergence in neuroanatomical representations, previous studies have failed to establish a functional link between language use and cognitive control. Here, we show that bilingual processing context activates a domain-general neural network underpinning both language processing and nonverbal executive function, thereby demonstrating an on-line interaction between bilingualism and enhancement in executive control.

One critical aspect of our findings is that performance was highly comparable in the Welsh (i.e., the native language) and the English (i.e., the second language) contexts, in the congruent and the incongruent conditions considered separately. This ensures that including incidental prime words did not have any confounding effect on flanker task execution per se but only established the desired language contexts, as verified by a postexperimental procedure (see Materials and Methods). Moreover, the bilingual context effect on enhancement in executive control was observed only in the case of incongruent stimuli, since error rates in incongruent trials and corresponding ERP amplitudes were reduced in the mixed block relative to the English and Welsh blocks, whereas congruent trials elicited no differences across the three blocks. This pattern of results suggests that a mixed-language context enhances the specific ability to inhibit irrelevant information when handling conflict but does not affect general cognitive functioning when conflict resolution is not required. In contrast with the current findings, between-subject comparisons have previously shown a relative advantage in bilinguals for processing both congruent and incongruent stimuli (Bialystok et al., 2004; Costa et al., 2008; Emmorey et al., 2008). In addition, the bilingual advantage is generally more pronounced for incongruent than congruent trials, leading to the usual observation of a reduced Simon effect. However, it is insufficient to conclude that bilinguals have greater executive control capacity than monolinguals because (1) the possibility remains that the reduced Simon effect results from a ceiling effect for congruent stimuli and (2) a generic advantage in executive control, as evidenced by facilitation in both congruent and incongruent trials, may be the consequence of various between-group differences. Therefore, results of the present within-subject study are more compatible with bilingualism bestowing cognitive benefits through enhancing executive mechanisms that are shared by bilingual lexical selection and nonverbal conflict resolution. However, it is important to note that the choice of tasks used to investigate executive control (i.e., the Simon and flanker tasks) may also contribute to the different results observed in the present and previous studies.

In a study comparing the performance of English monolinguals, early bilinguals, and bimodal bilinguals (who use both English and American Sign Language) in a flanker task, Emmorey et al. (2008) showed that bilinguals have enhanced executive function compared
Congruent
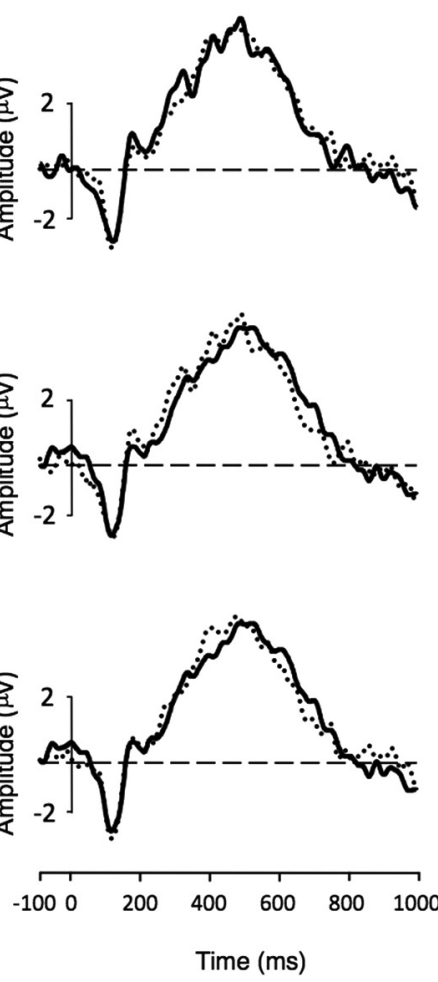

Incongruent

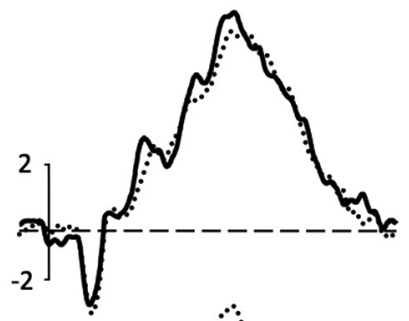

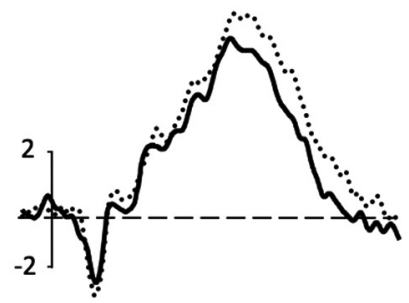

$\begin{array}{ccccc}-1000 \quad 200 & 400 \quad 600 \quad 800 \quad 1000 \\ & \text { Time (ms) }\end{array}$

Figure 4. ERPs of between-block comparisons: English-Welsh (top), Welsh-mixed (middle), and English-mixed (bottom) for the congruent (left) and incongruent (right) conditions. ERPs are a linear derivation of the electrodes shown on the schematic head.

with monolinguals and, surprisingly, also bimodal bilinguals, who did not differ from the monolinguals. The critical difference between unimodal and bimodal bilinguals is that the latter individuals switch between languages less frequently than the former (i.e., they tend to either sign or speak in a given interaction). Moreover, spoken and sign languages involve distinct perceptual and motor coordinators and therefore require minimal inhibitory control even when bimodal bilinguals sign and speak at the same time. Therefore, a bilingual advantage is only observed when the two languages are often used in a mixed-language context rather than two independent single-language contexts. The effect of language context in the same bilingual individuals described in the present study is consistent with this interpretation.

The finding that manipulating language-processing context spontaneously changes nonverbal cognitive performance has implications beyond the bilingual advantage, in the domain of functional plasticity. Functional plasticity, the process by which new skills and life experiences modify brain structure and functions (Rakic, 2002; Pascual-Leone et al., 2005), is known to be prompted by juggling (Draganski et al., 2004), taxi driving (Maguire et al., 2000), playing video games (Green and Bavelier, 2008), musical training (Elbert et al., 1995), and using multiple languages (Mechelli et al., 2004; Luk et al., 2011; Krizman et al., 2012). However, such neuroplastic changes reflect the "end product" of what is usually a long-term experience or training. Therefore, between-group contrasts do not capture the specific immediate effect of a given manipulated variable but rather the combined effect of many correlated factors over time. Here, we 
show that manipulating the current processing context within the same individuals modulates a brain mechanism shaped by longterm experience even though the context is irrelevant regarding the ongoing nonverbal task.

Future studies will need to investigate how the phenomenon established here interacts with (1) language proficiency and (2) language nonselective lexical access. A recent study shows that even relatively balanced bilinguals inhibit words more efficiently in one language than the other, suggesting that inhibition capacity may be determined by proficiency or usage (Ng and Wicha, 2013). Therefore, language proficiency may not only affect the overall magnitude of the effect but also the effectiveness of executive control in a duallanguage context. Bilinguals have been shown to activate both their languages when only one is presented (Thierry and $\mathrm{Wu}, 2007$; Wu and Thierry, 2010). Observing greater executive control benefits in the mixed-language compared with the single-language context suggests that only physically presented mixed languages generate sufficient conflict to modulate executive function. This hypothesis may be tested by obtaining measurements of language control and executive control simultaneously and investigating potential correlations between the two domains.

\section{References}

Abutalebi J, Annoni JM, Zimine I, Pegna AJ, Seghier ML, Lee-Jahnke H, Lazeyras F, Cappa SF, Khateb A (2008) Language control and lexical competition in bilinguals: an event-related FMRI study. Cereb Cortex 18:1496-1505. CrossRef Medline

Abutalebi J, Della Rosa PA, Green DW, Hernandez M, Scifo P, Keim R, Cappa SF, Costa A (2012) Bilingualism tunes the anterior cingulate cortex for conflict monitoring. Cereb Cortex 22:2076-2086. CrossRef Medline

Bialystok E (2001) Bilingualism in development: language, literacy, and cognition. New York: Cambridge UP.

Bialystok E (2007) Cognitive effects of bilingualism: how linguistic experience leads to cognitive change. IJBEB 10:210-223.

Bialystok E, Craik FI, Klein R, Viswanathan M (2004) Bilingualism, aging, and cognitive control: evidence from the Simon task. Psychol Aging 19: 290-303. CrossRef Medline

Bialystok E, Craik FI, Grady C, Chau W, Ishii R, Gunji A, Pantev C (2005) Effect of bilingualism on cognitive control in the Simon task: evidence from MEG. Neuroimage 24:40-49. CrossRef Medline

Bialystok E, Craik FI, Ryan J (2006) Executive control in a modified antisaccade task: effects of aging and bilingualism. J Exp Psychol Learn Mem Cogn 32:1341-1354. CrossRef Medline

Botvinick M, Nystrom LE, Fissell K, Carter CS, Cohen JD (1999) Conflict monitoring versus selection-for-action in anterior cingulate cortex. Nature 402:179-181. CrossRef Medline

Bradley MM, Lang PJ (1999) Affective Norms for English Words (ANEW): stimuli, instruction manual, and affective ratings. Gainesville, FL: University of Florida, Center for Research in Psychophysiology, Technical Report C-1.

Coltheart M (1981) The MRC psycholinguistic database. Q J Exp Psychol 33:497-505.

Costa A, Hernández M, Sebastián-Gallés N (2008) Bilingualism aids conflict resolution: evidence from the ANT task. Cognition 106:59-86. CrossRef Medline

Crinion J, Turner R, Grogan A, Hanakawa T, Noppeney U, Devlin JT, Aso T, Urayama S, Fukuyama H, Stockton K, Usui K, Green DW, Price CJ (2006) Language control in the bilingual brain. Science 312:1537-1540. CrossRef Medline

Draganski B, Gaser C, Busch V, Schuierer G, Bogdahn U, May A (2004) Neuroplasticity: changes in grey matter induced by training. Nature 427 : 311-312. CrossRef Medline

Elbert T, Pantev C, Wienbruch C, Rockstroh B, Taub E (1995) Increased cortical representation of the fingers of the left hand in string players. Science 270:305-307. CrossRef Medline

Emmorey K, Luk G, Pyers JE, Bialystok E (2008) The source of enhanced cognitive control in bilinguals: evidence from bimodal bilinguals. Psychol Sci 19:1201-1206. CrossRef Medline

Eriksen BA, Eriksen CW (1974) Effects of noise letters upon the identifica- tion of a target letter in a nonsearch task. Percept Psychophys 16:143-149. CrossRef

Fan J, McCandliss BD, Sommer T, Raz A, Posner MI (2002) Testing the efficiency and independence of attentional networks. J Cogn Neurosci 14:340-347. CrossRef Medline

Garbin G, Sanjuan A, Forn C, Bustamante JC, Rodriguez-Pujadas A, Belloch V, Hernandez M, Costa A, Avila C (2010) Bridging language and attention: brain basis of the impact of bilingualism on cognitive control. Neuroimage 53:1272-1278. CrossRef Medline

Gold BT, Kim C, Johnson NF, Kryscio RJ, Smith CD (2013) Lifelong bilingualism maintains neural efficiency for cognitive control in aging. J Neurosci 33:387-396. CrossRef Medline

Gratton G, Coles MG, Donchin E (1983) A new method for off-line removal of ocular artifact. Electroencephalogr Clin Neurophysiol 55:468-484. CrossRef Medline

Gratton G, Coles MG, Donchin E (1992) Optimizing the use of information: Strategic control of activation and responses. J Exp Psychol Gen 121:480-506. CrossRef Medline

Green CS, Bavelier D (2008) Exercising your brain: a review of human brain plasticity and training-induced learning. Psychol Aging 23:692-701. CrossRef Medline

Green DW (1998) Mental control of the bilingual lexico-semantic system. Biling: Lang Cogn 1:67-81. CrossRef

Kerns JG (2006) Anterior cingulate and prefrontal cortex activity in an FMRI study of trial-to-trial adjustments on the Simon task. Neuroimage 33:399-405. CrossRef Medline

Kerns JG, Cohen JD, MacDonald AW 3rd, Cho RY, Stenger VA, Carter CS (2004) Anterior cingulate conflict monitoring and adjustments in control. Science 303:1023-1026. CrossRef Medline

Kovács AM, Mehler J (2009) Cognitive gains in 7-month-old bilingual infants. Proc Natl Acad Sci U S A 106:6556-6560. CrossRef Medline

Krizman J, Marian V, Shook A, Skoe E, Kraus N (2012) Subcortical encoding of sound is enhanced in bilinguals and relates to executive function advantages. Proc Natl Acad Sci U S A 109:7877-7881. CrossRef Medline

Luk G, Bialystok E, Craik FI, Grady CL (2011) Lifelong bilingualism maintains white matter integrity in older adults. J Neurosci 31:16808-16813. CrossRef Medline

Maguire EA, Gadian DG, Johnsrude IS, Good CD, Ashburner J, Frackowiak RS, Frith CD (2000) Navigation-related structural change in the hippocampi of taxi drivers. Proc Natl Acad Sci U S A 97:4398-4403. CrossRef Medline

McCarthy G, Wood CC (1985) Scalp distributions of event-related potentials: an ambiguity associated with analysis of variance models. Electroencephalogr Clin Neurophysiol 62:203-208. CrossRef Medline

Mechelli A, Crinion JT, Noppeney U, O'Doherty J, Ashburner J, Frackowiak RS, Price CJ (2004) Neurolinguistics: structural plasticity in the bilingual brain. Nature 431:757. CrossRef Medline

Morton JB, Harper SN (2007) What did Simon say? Revisiting the bilingual advantage. Dev Sci 10:719-726. CrossRef Medline

Neuhaus AH, Urbanek C, Opgen-Rhein C, Hahn E, Ta TM, Koehler S, Gross M, Dettling M (2010) Event-related potentials associated with Attention Network Test. Int J Psychophysiol 76:72-79. CrossRef Medline

Ng S, Wicha NY (2013) Meaning first: a case for language-independent access to word meaning in the bilingual brain. Neuropsychologia 51:850863. CrossRef Medline

Oldfield RC (1971) The assessment and analysis of handedness: the Edinburgh inventory. Neuropsychologia 9:97-113. CrossRef Medline

Pascual-Leone A, Amedi A, Fregni F, Merabet LB (2005) The plastic human brain cortex. Annu Rev Neurosci 28:377-401. CrossRef Medline

Polich J (2007) Updating P300: an integrative theory of P3a and P3b. Clin Neurophysiol 118:2128-2148. CrossRef Medline

Rakic P (2002) Neurogenesis in adult primate neocortex: an evaluation of the evidence. Nat Rev Neurosci 3:65-71. CrossRef Medline

Rugg MD, Doyle MC, Melan C (1993) An event-related potential study of the effects of within- and across-modality word repetition. Lang Cogn Process 8:357-377. CrossRef

Sabbagh MA, Xu F, Carlson SM, Moses LJ, Lee K (2006) The development of executive functioning and theory of mind. A comparison of Chinese and U.S. preschoolers. Psychol Sci 17:74-81. CrossRef Medline

Thierry G, Wu YJ (2007) Brain potentials reveal unconscious translation during foreign-language comprehension. Proc Natl Acad Sci U S A 104: 12530-12535. CrossRef Medline 
Thierry G, Cardebat D, Démonet JF (2003) Electrophysiological comparison of grammatical processing and semantic processing of single spoken nouns. Brain Res Cogn Brain Res 17:535-547. CrossRef Medline
Wu YJ, Thierry G (2010) Investigating bilingual processing: the neglected role of language processing contexts. Front Psychol 1:178. CrossRef Medline 